\title{
TINGKAT PENGETAHUAN IBU BERSALIN TENTANG ROBEKAN JALAN LAHIR
}

\author{
Wahyuningsih ${ }^{1}$, Rizka Fatmawati ${ }^{2}$ \\ STIKES PKU Muhammadiyah Surakarta \\ Jl. Tulang Bawang Selatan No. 26 Tegalsari RT 02 RW 32 Kadipiro, Surakarta \\ rizkafatmawati@stikespku.ac.id
}

\begin{abstract}
Abstrak
Pendahuluan: Penanganan kejadian Rupture perineum dapat dengan mudah dilakukan oleh petugas kesehatan jika ibu telah memiliki pengetahuan tentang Rupture perineum, karena dengan baiknya pengetahuan maka dapat mengurangi tingkat kepanikan ibu melahirkan, yang memudahkan ibu untuk mendapatkan pelayanan. Berdasarkan studi pendahuluan yang dilakukan di Puskesmas Kebakkramat 1 Kabupaten Karanganyar pada tanggal 2 Januari 2016, selama tahun 2015 setidaknya terdapat 113 kejadian rupture perineum dari jumlah persalinan sebanyak 174 persalinan di Puskesmas Kebakkramat 1 Kabupaten Karanganyar.

Tujuan: Mengetahui Tingkat Pengetahuan Ibu Bersalin Tentang Robekan Jalan Lahir.

Metode Penelitian: Desain penelitian yang digunakan dalam penelitian ini adalah deskriptif dengan pendekatan Longitudinal dengan tehnik Analisa Univariat. Populasi yang digunakan dalam penelitian ini adalah semua ibu yang pernah bersalin di Puskesmas Kebakkramat 1 Karanganyar. Teknik pengambilan sampel yang digunakan adalah quota sampling. Jumlah sampel 30 responden. Instrumen yang digunakan dalam penelitian Tingkat Pengetahuan ini adalah kuesioner

Hasil: Tingkat pengetahuan ibu dalam kategori kurang yaitu ada 6 orang (20.0\%), kemudian responden dengan kategori cukup ada 16 orang $(53.3 \%)$ dan responden dengan tingkat pengetahuan baik, yaitu ada 8 orang $(26.7 \%)$.

Kesimpulan:Tingkat pengetahuan ibu bersalin tentang robekan jalan lahir di Puskesmas Kebakkramat 1 Kabupaten Karanganyar dalam kategori cukup.
\end{abstract}

Kata Kunci: Tingkat Pengetahuan, Ibu Bersalin, Robekan Jalan Lahir

\begin{abstract}
Background : The handling of the perineum rupture incident can easily be carried by health workers if the mother has knowledge of rupture perineum because, as by good news knowledge so it can reduce service the mother is panic, so that it is easy for mom to get service. Based on the introduction study that carried out at Puskesmas Kebakkramat 1 Karanganyar district on may 2 January 2016, in 2015 there was at least 113 perineum rupture incident of the 174 deliveries at the Puskesmas Kebakkramat 1 Karanganyar.

Purpose :to know the levelmothers knowledge about perineum rupture.

Design :The design of this researchwais discriptif with Longitudinal approacment the technic of analysis was univariat analysis. Population was all of the mothers who had labor at Puskesmas Kebakkramat 1 Kabupaten Karanganyar. The sampling technic was quota sampling type. Total sampling in this research was 30 respondents. The instrument in this research was questioner.

Result :the knowledge level in low category was 6 respondents $(20.0 \%)$. Respondents in middle category is 16 respondents $(53.3 \%)$. Respondents in high category was 8 respondent $(26.7 \%)$.

Conclusion :Maternal knowledge level of rupture perineum in Puskesmas Kebakkramat 1 Kabupaten Karanganyar is in middle category.
\end{abstract}

Keyword : knowledge level, maternal labour, rupture perineum 
Pendahuluan. Angka kematian ibu (AKI) pada wanita hamil dan bersalin adalah masalah besar di suatu negara. Menurut Survey Demografi dan Kesehatan Indonesia (SDKI) 2012 angka kematian ibu di Indonesia mencapai $\quad 359 / 100.000 \quad$ ibu hamil/melahirkan. Angka kematian ibu di Indonesia masih tergolong tinggi diantara negara-negara ASEAN, kemudian setelah Indonesia disusul oleh Vietnam 50/100.000 kelahiran hidup, Thailand 10/100.000 kelahiran hidup, Malaysia 5/100.000 kelahiran hidup, Singapura 3/100.000 kelahiran hidup.

Menurut WHO tahun 2010, di berbagai negara paling sedikit disebabkan oleh perdarahan, proporsinya berkisar antara kurang dari 10\% sampai hampir 60\% (PP dan KPA, 2010).

Di Indonesia diperkirakan ada 14 juta kasus perdarahan dalam kehamilan. Setiap tahunnya paling sedikit 128.000 perempuan mengalami perdarahan sampai meninggal. Perdarahan pasca persalinan terutama perdarahan postpartum primer merupakan perdarahan yang paling banyak menyebabkan kematian ibu. Perdarahan postpartum primer yaitu perdarahan seperempat dari seluruh kematian ibu

pasca persalinan yang terjadi dalam 24 jam pertama kelahiran (Faisal, 2008).

Angka kematian ibu di provinsi Jawa Tengah tahun 2012 berdasarkan laporan dari kabupaten/kota sebesar 116,34/100.000 kelahiran hidup, mengalami peningkatan bila dibandingkan dengan AKI pada tahun 2011 sebesar 116,01/100.000 kelahiran hidup. Beberapa faktor penyebab langsung kematian ibu di Indonesia masih didominasi oleh perdarahan (42\%), eklampsia/preeklampsia (13\%), abortus (11\%), infeksi (10\%), partus lama/persalinan macet (9\%), dan penyebab lain (15\%). Sedangkan faktor tidak langsung penyebab kematian ibu karena faktor terlambat (SDKI, 2012).

Angka kematian ibu di Karanganyar pada tahun 2014 sebesar 138,5/100.000 kelahiran hidup naik dibanding tahun 2013 (68,3/100.000 kelahiran hidup), tahun $2012(127,1 / 100.000$ kelahiran hidup), tahun $2011 \quad(99,1 / 100.000$ kelahiran hidup), tahun 2010 (128,6/100.000 kelahiran hidup), serta tahun $2009(64,9 / 100.000$ kelahiran hidup). Jumlah kasus kematian ibu tahun 2014 sebanyak 18 kasus yang tersebar di wilayah Puskesmas Jumapolo 3 orang, Jumantono 1 orang, Matesih 2 orang, Tawangmangu 1 orang, Ngargoyoso 3 orang, 
Karangpandan 1 orang, Karanganyar 3 orang, Tasikmadu 1 orang, Colomadu I 1 orang dan Kebakkramat I 2 orang (Profil Kesehatan Kabupaten Karanganyar Tahun 2014).

Persalinan dengan rupture perineum apabila tidak ditangani secara efektif menyebabkan perdarahan dan infeksi menjadi lebih berat, serta pada jangka waktu panjang dapat mengganggu ketidaknyamanan ibu dalam hal hubungan seksual (Mochtar, 2007).

Pengetahuan adalah hasil pengindraan manusia, atau hasil tahu seseorang terhadap objek melalui indra yang dimilikinya (mata, hidung, telinga, dan sebagainya). Dengan sendirinya, pada waktu pengindraan sampai menghasilkan pengetahuan tersebut sangat dipengaruhi oleh intensitas perhatian dan persepsi terhadap objek. Sebagian besar pengetahuan seseorang diperoleh melalui indra pendengaran yaitu telinga dan indra penglihatan yaitu mata (Notoatmodjo, 2012)

Penanganan kejadian Rupture perineum dapat dengan mudah dilakukan oleh petugas kesehatan jika ibu telah memiliki pengetahuan tentang Rupture perineum, karena dengan baiknya pengetahuan maka dapat mengurangi tingkat kepanikan ibu melahirkan, yang memudahkan ibu untuk mendapatkan pelayanan.

Terjadinya Rupture perineum sebagian besar ibu dikarenakan posisi persalinan, dan cara cara meneran yang kurang tepat. Sehingga sebagian besar kasus ibu melahirkan mengalami luka robekan jalan lahir. Untuk itu perlu adanya pengetahuan tentang luka robekan jalan lahir pada ibu yang akan melahirkan sehingga ibu akan mudah mendapatkan pelayanan kesehatan.

Persalinan dengan rupture perineum apabila tidak ditangani secara efektif menyebabkan perdarahan dan infeksi menjadi lebih berat, serta pada jangka waktu panjang dapat mengganggu ketidaknyamanan ibu dalam hal hubungan seksual (Mochtar, 2007).

Berdasarkan studi pendahuluan yang dilakukan di Puskesmas Kebakkramat 1 Kabupaten Karanganyar pada tanggal 2 Januari 2016, selama tahun 2015 setidaknya terdapat 113 kejadian rupture perineum dari jumlah persalinan sebanyak 174 persalinan di Puskesmas Kebakkramat $\quad 1 \quad$ Kabupaten Karanganyar.

Berdasarkan latar belakang diatas maka tujuan penelitian ini adalah Untuk mengetahui tingkat pengetahuan ibu bersalin tentang Robekan Jalan Lahir di Puskesmas 
Kebakkramat 1 Kabupaten

Karanganyar.

Metode. Jenis penelitian ini menggunakan deskriptif, yaitu metode yang digunakan untuk menggambarkan atau menganalisis suatu hasil penelitian tetapi tidak digunakan untuk membuat kesimpulan yang lebih luas. Berdasarkan waktunya penelitian ini dilakukan dengan pendekatan cross sectional.

Lokasi penelitaian di Puskesmas Kebakkramat 1 Kabupaten Karanganyar. Penelitian ini telah dilaksanakan pada tanggal 8 April sampai Agustus 2016.

Populasi dalam penelitian ini adalah ibu yang pernah mengalami persalinan normal di Puskesmas Kebakkramat 1 Kabupaten Karanganyar selama bulan April 2016 sampai dengan juli 2016 dengan Jumlah populasi sebanyak 55 ibu bersalin.

Pada penelitian ini jumlah sampel yang digunakan sebanyak Quota Sample. Dalam penelitian ini digunakan sampel sebanyak 30 sampel.

Kriteria Sampel dalam penelitian ini yaitu :

1) Inklusi

Menurut Murti (2010), kriteria inklusi adalah kriteria yang menjadi batasan untuk menentukan subjek yang masuk ke dalam penelitian yaitu:

a) Ibu yang pernah mengalami persalinan fisiologis di Puskesmas Kebakkramat 1 Kabupaten Karanganyar

b) Ibu yang pernah mengalami persalinan fisiologis di Puskesmas Kebakkramat1Kabupaten Karanganyar yang bersedia dijadikan responden

c) Ibu yang pernah mengalami persalinan fisiologis di Puskesmas Kebakkramat 1 Kabupaten Karanganyar yang berumur antara 20 sampai dengan 35 tahun

2) Eksklusi

Menurut Murti (2010), kriteria eksklusi adalah subjek yang harus dikeluarkan dari penelitian karena berbagai sebab yang dapat mempengaruhi penelitian seperti terdapat keadaan yang tidak memungkinkan untuk dilakukan penelitian yaitu, tidak dapat membaca dan menulis.

Subjek yang harus dikeluarkan dalam penelitian ini adalah :

a) Ibu yang pernah bersalin di Puskesmas Kebakkramat 1 Kabupaten Karanganyar dengan komplikasi 
b) Ibu yang pernah bersalin di Puskesmas Kebakkramat 1 Kabupaten Karanganyar dengan gangguan psikologis

c) Ibu yang pernah bersalin di Puskesmas Kebakkramat 1 Kabupaten Karanganyar yang berumur antara 20 sampai dengan 35 tahun

Tehnik pengumpulan data menggunakan data primer dan sekunder. Pengumpulan data primer yang dilakukan dalam penelitian ini adalah dengan mengisi lembar kuesioner dan wawancara, sedangkan data sekunder dalam penelitian ini adalah catatan data persalinan di Puskesmas Kebakkramat 1 Kabupaten Karanganyar.

Tehnik pengolahan data menggunakan Editing, Coding, Scoring, Data Entri.

Tehnik analisa data menggunakan analisis univariat.

\section{Hasil dan pembahasan.}

1. Karakteristik Responden

a. Usia

Distribusi Frekuensi Responden Berdasarkan Usia

\begin{tabular}{lcc}
\hline Usia & Frekuensi & Prosentase $(\%)$ \\
\hline$<20$ tahun & 2 & 6.7 \\
$20-35$ tahun & 23 & 76.7
\end{tabular}

\begin{tabular}{lcc}
$>35$ tahun & 5 & 16.7 \\
Total & 30 & 100.0 \\
\hline
\end{tabular}

Berdasarkan tabel diatas diketahui bahwa mayoritas responden dengan usia 20-35 tahun yaitu ada 23 orang (76,7\%), dan minoritas responden dengan usia $<2($ tahun, yaitu ada 2 orang $(6,7 \%)$.

b. Pendidikan

Distribusi Frekuensi Responden Berdasarkan Pendidikan

\begin{tabular}{lcc}
\hline Pendidikan & Frekuensi & $\begin{array}{c}\text { Prosentas } \\
\mathrm{e}(\%)\end{array}$ \\
\hline $\begin{array}{l}\text { Pendidikan Rendah } \\
\text { Pendidikan }\end{array}$ & 9 & 30.0 \\
Menengah & 19 & 63.3 \\
Pendidikan Tinggi & 2 & 6.7 \\
Total & 30 & 100.0 \\
\hline
\end{tabular}

Berdasarkan tabel diatas diketahui bahwa mayoritas responden dengan pendidikan menengah yaitu ada 19 orang (63,3\%), dan minoritas responden dengan pendidikan tinggi, yaitu ada 2 orang $(6,7 \%)$.

c. Pekerjaan

Distribusi Frekuensi Responden Berdasarkan Pekerjaan

\begin{tabular}{lcc}
\hline Pekerjaan & Frekuensi & Prosentase (\%) \\
\hline IRT & 14 & 46.7 \\
Swasta & 11 & 36.7 \\
Wiraswasta & 5 & 16.7 \\
Total & 30 & 100.0 \\
\hline
\end{tabular}


Berdasarkan tabel diatas

diketahui bahwa mayoritas

responden dengan pekerjaan

IRT yaitu ada 14 orang (46,7\%),

dan minoritas responden dengan

pekerjaan wiraswasta, yaitu ada

5 orang $(16,7 \%)$.

d. Paritas

Distribusi Frekuensi Responden

Berdasarkan Pekerjaan

\begin{tabular}{lcc}
\hline Paritas & Frekuensi & $\begin{array}{c}\text { Prosentas } \\
\text { e (\%) }\end{array}$ \\
\hline Primipara & 15 & 50.0 \\
Multipara & 12 & 40.0 \\
Grandemultipara & 3 & 10.0 \\
Total & 30 & 100.0 \\
\hline
\end{tabular}

Berdasarkan tabel diatas

diketahui bahwa mayoritas

responden dengan paritas

primipara yaitu ada 15 orang $(50.0 \%)$

e. Jenis Persalinan

Distribusi Frekuensi Responden

Berdasarkan Jenis Persalinan

\begin{tabular}{lcc}
\hline Persalinan & Frekuensi & Prosentase (\%) \\
\hline Normal & 18 & 60.0 \\
Pacuan & 5 & 16.7 \\
Vakum & 7 & 23.3 \\
Total & 30 & 100.0 \\
\hline
\end{tabular}

Berdasarkan tabel diatas

diketahui bahwa mayoritas

responden dengan jenis

persalinan normal yaitu ada 18

orang $(60.0 \%)$.
2. Pengetahuan Ibu Bersalin

Tentang Robekan Jalan Lahir

Distribusi

Frekuensi

Responden

Berdasarkan

Pengetahuan Tentang Robekan

Jalan Lahir

\begin{tabular}{lcc}
\hline Pegetahuan & Frekuensi & Prosentase (\%) \\
\hline Kurang & 6 & 20.0 \\
Cukup & 16 & 53.3 \\
Baik & 8 & 26.7 \\
Total & 30 & 100.0 \\
\hline
\end{tabular}

Hasil penelitian diatas menunjukan bahwa mayoritas responden dengan tingkat pengetahuan tentang robekan jalan lahir yang meliputi pengertian robekan jalan lahir, klasifikasi robekan jalan lahir, tingkatan \& penanganan luka robekan jalan lahir, prosedur hecting perineum dalam kategori cukup yaitu ada 16 orang (53,3\%). pengetahuan ibu bersalin tentang robekan jalan lahir.

Pembahasan. Hasil penelitian ini menunjukan bahwa mayoritas responden dengan tingkat pengetahuan tentang robekan jalan lahir dalam kategori cukup yaitu ada 16 orang (53,3\%). Dimana pengetahuan dalam artian pengetahuan ibu bersalin tentang robekan jalan lahir yang meliputi pengertian robekan jalan lahir, klasifikasi robekan jalan lahir, tingkatan 
\& penanganan luka robekan jalan lahir, prosedur hecting perineum.

Terjadinya Rupture perineum sebagian besar ibu dikarenakan posisi persalinan, dan cara cara meneran yang kurang tepat. Sehingga sebagian besar kasus ibu melahirkan mengalami luka robekan jalan lahir. Untuk itu perlu adanya pengetahuan tentang luka robekan jalan lahir pada ibu yang akan melahirkan sehingga ibu akan mudah mendapatkan pelayanan kesehatan.

Penanganan kejadian Rupture perineum dapat dengan mudah dilakukan oleh petugas kesehatan jika ibu telah memiliki pengetahuan tentang Rupture perineum, karena dengan baiknya pengetahuan maka dapat mengurangi tingkat kepanikan ibu melahirkan, yang memudahkan ibu untuk mendapatkan pelayanan

Dalam penelitian ini, mayoritas responden memiliki umur 20-35 tahun yaitu ada 23 responden (76,7\%). Ibu yang telah memiliki usia 20 tahun sudah dapat dikatakan sudah cukup mampu untuk menggunakan kognitifnya dalam menerima atau mencari pengetahuan. Dengan demikian dapat dikatakan bahwa pada usia tersebut seseorang memiliki kesempatan memperoleh pengetahuan tentang robekan jalan lahir.
Umur merupakan salah satu faktor yang dapat mempengaruhi tingkat pengetahuan seseorang. Mubarok (2007:30) menyebutkan bahwa bertambahnya umur seseorang dapat berpengaruh pada pertambahan pengetahuan yang diperoleh, akan tetapi pada umur-umur tertentu atau menjelang usia lanjut kemampuan penerimaan atau mengingat suatu pengetahuan akan berkurang.

Dalam penelitian ini mayoritas responden memiliki tingkat pendidikan menegah yaitu sebanyak 19 orang (63.3\%).Hal ini disebabkan karena faktor ekonomi dan lingkungan. Sebagian besar responden lebih memilih untuk bekerja daripada melanjutkan sekolah ke jenjang lebih tinggi atau perguruan tinggi. Dengan bekerja mereka bisa membantu keluarga dalam memenuhi kebutuhan hidup. Setelah mencukupi usianya dan menemukan jodoh, mereka kemudian menikah. Akan tetapi pada tingkat pendidikan SMA sudah cukup untuk mendapatkan pengetahuan, dalam hal ini tentang robekan jalan lahir.

Selain umur, pendidikan juga menjadi salah satu faktor dalam mempengaruhi seseorang untuk memperoleh pengetahuan. Sebagaimana yang diungkapkan Mubarok (2011, hal 
83-84) bahwa pendidikan merupakan bimbingan yang di berikan seseorang kepada orang lain agar dapat memahami sesuatu hal. Tidak dapat dipungkiri bahwa makin tinggi pendidikan seseorang, semakin mudah pula mereka menerima informasi, dan pada akhirnya pengetahuan yang dimilikinya akan semakin banyak.

Dalam penelitian ini mayoritas responden memiliki status pekerjaan sebagai IRT yaitu ada 46,7\%. Hal ini terjadi karena mencari pekerjaan bukanlah suatu yang mudah didapat, selain karena adanya pertimbangan dalam membagi tugas rumah tangga seperti mengurus anak. Kekhawatiran akan resiko kurangnya perhatian terhadap anak menjadi salah satu fakor kenapa responden lebih memilih tidak bekerja atau keluar dari pekerjaannya dan berkonsentrasi sebagai ibu rumah tangga. Akan tetapi, bukan berarti mereka tidak bisa memperoleh pengetahuan, khususnya mengenai persiapan persalinan di Rumah Bersalin. Pengetahuan bisa didapat dari lingkungan dan pergaulan mereka. Dengan demikian pengetahuan mengenai tentang robekan jalan lahir bisa didapatkan melalui interaksi responden di lingkungan tempat tinggal mereka.
Pekerjaan merupakan faktor lain yang dapat mempengaruhi seseorang memperoleh pengetahuan. Mubarok (2011: 83-84), menyebutkan bahwa lingkungan pekerjaan memungkinkan seseorang berinteraksi dengan orang lain sehingga di dalam interaksi tersebut memungkinkan untuk mendapatkan pengetahuan. Lingkungan pekerjaan dapat membuat seseorang memperoleh pengalaman dan pengetahuan, baik secara langsung maupun secara tidak langsung.

Dalam penelitian ini mayoritas responden memiliki paritas primipara, dengan frekuensi sebanyak 15 orang (50.0\%). Ibu yang dengan status paritas primipara memang tidak memiliki pengalaman yang banyak, akan tetapi biasanya ibu akan mencari informasi atau diberi tahu oleh petugas kesehatan. Dengan demikian pada ibu primipara memiliki kesepatan untuk mendapatkan pengetahuan, dalam hal ini tentang tentang robekan jalan lahir.

Paritas merupakan faktor lain yang dapat mempengaruhi seseorang memperoleh pengetahuan. Menurut Sari (2008), Pengalaman merupakan guru yang terbaik. Pepatah tersebut dapat diartikan bahwa pengalaman itu suatu cara untuk memperoleh kebenaran pengetahuan. Oleh sebab itu, 
pengalaman pribadi pun dapat digunakan sebagai upaya untuk memperoleh pengetahuan. Pengalaman dalam hal ini adalah pengalaman melahirkan atau paritas.

Dalam penelitian ini didapatkan hasil bahwa mayoritas responden dengan jenis persalinan normal yaitu ada 18 orang $(60.0 \%)$.

Persalinan adalah proses di mana bayi, plasenta dan selaput ketuban keluar dari uterus. Persalinan di anggap normal jika prosesnya terjadi pada usia kehamilan cukup bulan (setelah 37 minggu) tanpa di sertai adanya penyulit (Asuhan persalinan normal, JNPKKR, 2008).

Sedangkan menurut Saifuddin, 2009, Persalinan dan kelahiran normal adalah proses pengeluaran janin yang terjadi pada kehamilan cukup bulan (3742 minggu), lahir spontan dengan presentasi belakang kepala yang berlangsung dalam 18 jam tanpa komplikasi baik pada ibu maupun pada janin.

Persalinan normal adalah pengeluaran bayi dengan usia kehamilan cukup bulan, letak memanjang atau sejajar sumbu badan ibu, presentasi belakang kepala, keseimbangan diameter kepala bayi dan panggul ibu, serta dengan tenaga ibu sendiri (Prawirohardjo, 2009)

Berdasarkan uraian diatas maka peneliti berasumsi bahwa sebagian besar ibu bersalin di Puskesmas Kebakkramat 1 Kabupaten Karanganyar dengan pengetahuan tentang robekan jalan lahir dalam kategori cukup. Antara teori dan hasil tidak ada kesenjangan dalam penelitian ini.Umur, status pekerjaan, paritas, dan jenis persalinan saling mempengaruhi hasil dalam penelitian ini.

Kesimpulan. Berdasarkan hasil penelitian yang telah dilakukan pada 30 responden ibu bersalin di Puskesmas Kebakkramat 1 Kabupaten Karanganyar maka dapat disimpulkan bahwa tingkat pengetahuan responden tentang robekan jalan lahir mayoritas responden dengan pengetahuan dalam kategori cukup yaitu ada 16 orang $(53,3 \%)$.

Saran. Disarankan responden untuk meningkatkan pengetahuan yang cukup tentang robekan jalan lahir agar responden tidak cemas serta agar bisa dipraktekkan dalam nanti sewaktu bersalin dikemudian hari. pengetahuan ini dapat didapatkan dari media elektronik atau juga bertanya kepada petugas kesehatan.

Bagi Profesi Kebidanan. Disarankan untuk memberikan edukasi yang lebih 
kepada ibu bersalin salah satunya adalah tentang luka robekan jalan lahir, macam-macam robekan jalan lahir serta penanganan seputar robekan jalan lahir sebelum terjadinya proses persalinan.

Bagi Institusi Kebidanan. Disarankan untuk institusi bisa lebih menjadikan hasil penelitian ini sebagai salah satu bahan acuan terbaru bagi institusi terkhusus dalam hal robekan jalan lahir.

Bagi Peneliti. Disarankan untuk peneliti lain dapat menjadikan penelitian ini sebagai referensi untuk mengembangkan hasil penelitian ini menjadi lebih sempurna.

\section{Daftar pustaka}

Cahyaning SH, 2009. Hubungan Antara Paritas dengan Kejadian Rupture Perineum Spontan di RSUD Kota Surakarta. Surakarta

Dewi S, 2013. Gambaran Kejadian Rupture Perineum di Rumah Sakit Ibu dan Anak Badrul Aini. Medan

Dina. D. Seweng. Nyorong. 2013. Faktor Determinan Kejadian Perdarahan Post Partum di Rsud Majene Kabupaten mejene. Sulawesi Barat.

Enggar P, Y. Hubungan berat badan lahir dengan kejadian rupture perineum pada persalinan normal di RB Harapan Bunda di Surakarta. Surakarta : Jurnal Kesehatan. 2010.
Hidayat, A.A.A 2011. Metode Penelitian Kebidanan dan Teknik Analisis Data. (http://dilihatya.com/2246/pengert ian-daftar-pustaka-menurut-paraahli)

Meliono, irmayanti, dkk. 2007. Jurnal ilmiah STIKES U'Budiyah Vol.2, No.1. Kusumah wijaya dan dwitagama dedi. 2011. Mengenal penelitian tindakan kelas. Jakarta: pt indeks. MPKT Modul 1. Jakarta: Lembaga Penerbitan FEUI.).

Murti, B.2010. Desain dan Ukuran Sampel untuk Penelitian Kuantitatif dan Kualitatif di Bidang Kesehatan. Yogyakarta: UGM Press.

Notoatmodjo, S. 2010. Metodologi Penelitian Kesehatan. Jakarta: Rineka Cipta. Jakarta : Salemba Medika

Prawirohardjo, dkk. 2008. Ilmu Kandungan. Jakarta: PT Bina Pustaka Sarwono Prawirohardjo.

Prawirohardjo, (2010), ilmu Kebidanan. Jakarta : Yayasan Bina Pustaka

Sarwono Prawirohardjo. Sugiyono, 2010. Metode penelitian pendidikan. Bandung: alfabeta.

Setiawan, A. Saryono. 2010. Metodologi Penelitian Kebidanan DIII, DIV, SI dan S2. Yogyakarta: Nuha Medika

Setiawan, N. 2011. Diklat Metodologi Penelitian Sosial: Teknik Sampling. Departemen Pendidikan Nasional 
Sugiyono. 2011. metode penelitian, pendidikan pendekatan kuantitatif, kualitatif, dan $R \& D$ ). Bandung : Alfabeta
Sujiyatini, dkk. 2011. Asuhan Kebidanan II (PERSALINAN). Yogyakarta: Rohima Press

Varney, H. (2010). Buku ajar asuhan kebidanan, ed. 4, vol. 1. Jakarta : EGC. 
